\title{
A Study on Broiler Farming Practices Followed by the Farmers in Mizoram
}

\author{
Lalruatfela Sailo and Samares Kumar Das* \\ Dept. of Veterinary \& Animal Husbandry Extension, College of Veterinary Sciences \& Animal Husbandry, Central Agricultural \\ University, Selesih, Aizawl, Mizoram (796 015), India
}

\section{Corresponding Author}

Samares Kumar Das

e-mail: samcau.d1@gmail.com

\author{
Article History \\ Article ID: AR1879 \\ Received in $23^{\text {rd }}$ June, 2018 \\ Received in revised form $24^{\text {th }}$ August, 2018 \\ Accepted in final form $27^{\text {th }}$ August, 2018
}

\begin{abstract}
Broiler farming practices followed by the broiler farmers in Mizoram were studied to help R\&D professionals take measures to improve the situation. From eight districts in Mizoram two (Aizawl and Kolasib), from each district two blocks and from each block five villages were selected purposively having maximum number of broiler farms, and from each village five farmers engaged in broiler farming were selected randomly to have a total of 100 respondents who were interviewed using a pre-tested semi-structured interview schedule. With a medium flock size (300-1,000,66\%) they purchased feed mainly from the feed dealer (41\%) 3,200-16,000 kg feed (57\%) spending ₹ 95,000 $4,80,000(53 \%)$ in a year they housed their birds intensively (69\%). Cleaning the poultry houses by sweeping and washing with plain water $39 \%$ buried the dead birds. Treating the birds mainly by themselves (63\%) farmers vaccinated their flocks against IBD (47\%) and ND (30\%) with little concern about the vaccination schedule. With an average ₹ 45 per chick, ₹ 150 per kg live bird and ₹ 38 per kg feed farmers sold their birds at 3 months weighing $3 \mathrm{~kg}$ majority (54\%) sold their birds in the village. Measures should be taken to make the farmers aware of the need for vaccination on time and the need for adopting a scientific system of rearing. Marketing and veterinary services should be provided to improve the situation.
\end{abstract}

Keywords: Mizoram, broiler, farming practice, adoption, constraint

\section{Introduction}

In India, poultry farming has transformed from backyard rearing to commercially organized industry in last five decades. Due to its significant role in socio-economy of rural poor by generating gainful employment, providing food security and fulfilling small cash needs, poultry farming has been accepted as one of the means of rural development. India is the second largest egg producer and third largest broiler-chicken producer in the world (Pratab and Carin, 2015) with 69.73 billion eggs produced at the beginning of the Twelfth Five-Year Plan (Rath et al., 2015). Poultry rearing has been a traditional practice in Mizoram since time unknown. Mizo people rear poultry in the backyard on home grown feed with cheap housing made of locally available materials like woods, bamboo, etc. (Angela, 2014). However, poultry production in Mizoram has taken a new turn in the late eighties with establishment of broiler farms in various parts of the state. Though there is no large scale poultry farm in Mizoram, almost $70 \%$ of the farmers keep poultry for subsidiary income. The estimated number of broilers available for consumption in the state during 2012-13 was 847,763 and net meat production was $1,561 \mathrm{t}$. The per capita availability of broiler meat for the year
2012-13 was estimated at $1.39 \mathrm{~kg}$ per year (Rahman, 2015). Various government and non-government organizations and institutions act at different levels to generate and transfer poultry technologies to the farmers. Despite these efforts adoption of recommended technologies in poultry farming has not been as widespread as anticipated. The reasons for poor adoption of poultry farming technologies are yet to be fully understood. Though studies have been conducted in other states of India, studies on broiler farming are rare in Mizoram. Keeping this in view a study was undertaken on the broiler farming practices followed by the farmers in Mizoram to help $R \& D$ professionals take measures to improve the situation.

\section{Materials and Methods}

Out of eight districts in the state, two districts, Aizawl and Kolasib, were selected purposively having maximum number of broiler farms. From each district, two development blocks and from each block five villages were selected purposively based on the number of broiler farms. So, a total of 20 villages were selected. From each village five farmers engaged in broiler farming were selected randomly. So, the total number of respondents for the study was 100, i.e. 50 from each district. For the purpose of data collection a semi-structured interview 
schedule was prepared covering all the objectives which was pre-tested. Observation was judiciously done to complement and supplement data collected by interview schedule. Secondary data were collected from the published reports, statistical handbooks, economic survey reports, journals and newspapers, etc. The collected data were compiled, tabulated and analyzed using percentage, frequency and chi-square test using Statistical Package for the Social Sciences (SPSS).

\section{Results and Discussion}

\subsection{Flock size}

A look into Table 1 reveals that majority of the respondents (66\%) had medium size (300-1,000 birds) followed by small size $(25 \%, 100-300$ birds) and large size $(9 \%, 1,000$ and above birds) flock.

Mozumdar et al. (2009) found that small broiler farmers (300-2,000 birds) dominated the rural areas of Mymensingh in Bangladesh. Flock size of 300-1,000 birds was very less in comparison to other states of India. It might be due to difficulty in marketing, high cost of feed, lack of transportation, and unavailability of land and space.

\begin{tabular}{lcc}
\hline \multicolumn{3}{l}{ Table 1: Flock size owned by the respondents } \\
\hline Category & $\begin{array}{c}\text { Frequency and per- } \\
\text { centage }(\mathrm{N}=100)\end{array}$ & Mean \pm SD \\
\hline Small size (100-300) & 25 & $688.45 \pm 374.09$ \\
Medium size (300- & 66 & \\
$1,000)$ & 9 \\
Large size (1,000 & \\
and above) & \\
\hline$\chi^{2}=42.172$ at 2 df (Non-significant)
\end{tabular}

\subsection{Feeding}

\subsubsection{Sources of feed}

As shown in Table 2 a good number of respondents (41\%) procured feed from the feed dealer only followed by open market only (20\%), open market and feed dealer (15\%), government source and feed dealer (11\%), government source only (7\%), and open market and government source (6\%).

\begin{tabular}{lc}
\hline Table 2: Sources of feed & \\
\hline Sources & $\begin{array}{c}\text { Frequency and per- } \\
\text { centages ( } \mathrm{N}=100)\end{array}$ \\
\hline Open market & 20 \\
Feed dealer & 41 \\
Government source & 7 \\
Open market and feed dealer & 15 \\
Open market and government source & 6 \\
Government source and feed dealer & 11 \\
\hline
\end{tabular}

$\chi^{2}=0.209$ at $5 \mathrm{df}$ (Non-significant)
Most of the respondents procured feed from the feed dealer and open market only. A few procured from the government source. It might be so because feed from the feed dealer and open market was always available but in case of the government they had to wait for a specific time. Feed companies like Amrit Feed, Samrat Feed and Godrej Feed supplied feed in the study area. Elizabeth (2012) founded that feeds and feed ingredients in Mizoram were obtained from other states hence cost of the feeds became high which accounted for higher market price of broiler.

\subsubsection{Feed purchased in a year}

Table 3 reveals that majority of the respondents (57\%) purchased 3,200-16,000 kg feed followed by 30 percent purchased above 16,000 kg feed and 13 percent purchased less than 3,200 kg feed in the last 12 months.

Most of the farmers purchased feed between $3,200-16,000 \mathrm{~kg}$ in one year which was less in comparison to other farmers in other states as most of the farmers were small farmers with less flock size.

\begin{tabular}{lcc}
\hline \multicolumn{3}{l}{ Table 3: Feed purchased in the last 12 months } \\
\hline $\begin{array}{l}\text { Quantity purchased } \\
(\mathrm{kg})\end{array}$ & $\begin{array}{c}\text { Frequency and per- } \\
\text { centage }(\mathrm{N}=100)\end{array}$ & Mean \pm SD \\
\hline Below 3,200 & 13 & $9479.55 \pm$ \\
$3,200-16,000$ & 57 & 6327.053 \\
Above 16,000 & 30 & \\
$\chi^{2}=52.546$ at 2 df (Non-significant)
\end{tabular}

\subsubsection{Expenditure on feeding in a year}

Majority of the respondents (53\%) spent ₹ 95,000-4,80,000 for purchasing feed followed by $29 \%$ spending more than $₹ 4,80,000$ and 18 percent spent less than $₹ 95,000$ for purchasing of broiler feeds (Table 4).

Expenditure on feed was higher in comparison to flock size which might be due to higher cost of feed and transportation. Banday and Risam (2001) reported that feed was the single largest item which accounted for about 80 percent of the total cost of poultry enterprise.

\begin{tabular}{lcc}
\hline \multicolumn{3}{l}{ Table 4: Expenditure on feed in last 12 months } \\
\hline $\begin{array}{l}\text { Expenditure (₹) } \\
\text { Frequency and per- } \\
\text { centage }(\mathrm{N}=100)\end{array}$ & Mean \pm SD \\
\hline Below 95,000 & 18 & $286975.76 \pm$ \\
$95,000-4,80,000$ & 53 & 192087.48 \\
Above 4,80,000 & 29 & \\
\hline$\chi^{2}=63.352$ at 2 df (Non-significant) & \\
3.3. Housing & \\
3.3.1. Housing type
\end{tabular}

Result reveals that nearly two-third of the respondents (69\%) 
followed intensive system of housing with elevated floor made of bamboo or wood followed by intensive housing with floor on the ground (31\%). However, none of them followed semiintensive or free range type of housing (Table 5).

According to Rahman (2015), majority of the farmers (92\%) reared adult birds in raised slatted floor (platform) made up of bamboo. Most of the broiler houses were intensive type with elevated floor which might be due to the fact that Mizoram was a hilly area and it was difficult to find a plain area for housing. Poultry houses were constructed on the slope of the hill with bamboo or wooden floor. Walls of the house were made of bamboo, wood, plastic, metal sheet, etc. The roof was made of metal sheet. Owing to heavy rainfall it was wise to use elevated floor and metal sheet roof.

\begin{tabular}{lc}
\hline Table 5: Type of housing followed by the respondents \\
\hline Type & $\begin{array}{c}\text { Frequency and per- } \\
\text { centage }(\mathrm{N}=100)\end{array}$ \\
\hline Intensive with elevated floor & 69 \\
Intensive with floor on the ground & 31 \\
Semi-intensive & 0 \\
Free range & 0 \\
\hline
\end{tabular}

$\chi^{2}=1.169$ at $3 \mathrm{df}$ (Non-significant)

\subsubsection{Expenditure on housing}

Majority of the respondents (54\%) spent ₹ 4,300-12,400, 25 percent spent more than $₹ 12,400$ and $21 \%$ of the respondents spent less than ₹ 4,300 on broiler housing (Table 6).

Expenditure on housing was less which might be due to the reason that farmers used locally available cheap materials for construction of their poultry houses.

\begin{tabular}{lcc}
\hline \multicolumn{3}{l}{ Table 6: Expenditure on housing } \\
\hline Expenditure $(₹)$ & $\begin{array}{c}\text { Frequency and per- } \\
\text { centage }(\mathrm{N}=100)\end{array}$ & Mean \pm SD \\
\hline Below 4,300 & 21 & $8333.33 \pm$ \\
$4,300-12,400$ & 54 & 4062.02 \\
Above 12,400 & 25 & \\
\hline
\end{tabular}

$\chi^{2}=54.784$ at $2 \mathrm{df}$ (Non-significant)

\subsubsection{Cleaning of the shed}

All the respondents disinfected and cleaned their poultry sheds by sweeping followed by washing with plain water, while 85 percent of the respondents used potassium permanganate $\left(\mathrm{KMnO}_{4}\right.$ ) treated water to clean and disinfect the sheds (Table 7).

Bolder and Ledoux (2002) reported that cleaning was basically the management of dirt that could be seen partially to separate and remove this dirt from a surface by means of water and detergent. Most of the farmers swept and washed the shed with $\mathrm{KMnO}_{4}$ water might be due to the reason that it was easy to do and due to lack of knowledge of or inconvenience related to other methods of disinfectation.

\begin{tabular}{lc}
\hline \multicolumn{2}{l}{ Table 7: Cleaning of the poultry house } \\
\hline Mode of cleaning & $\begin{array}{r}\text { Frequency and percentage } \\
\text { ( } \mathrm{N}=100)\end{array}$ \\
\hline By sweeping & 100 \\
By washing with plain water & 100 \\
By washing with $\mathrm{KMnO}_{4}$ water & 85 \\
\hline$\chi^{2}=0.417$ at $2 \mathrm{df}(\mathrm{Non}-$ significant)
\end{tabular}

\subsubsection{Disposal of the dead birds}

Table 8 shows that $39 \%$ of the respondents buried the dead birds, $23 \%$ threw away in the open areas and $38 \%$ of the respondents did both as per their convenience.

Adekomaya (2012) also found that approximately 95\% of the poultry farmers globally used burial pits to dispose the dead birds. Most of the farmers buried their dead birds under the ground which was one of the conventional methods in the villages. Also a few farmers threw away in the open areas in less populated areas as a means of disposing the dead birds.

\begin{tabular}{lc}
\hline \multicolumn{2}{l}{ Table 8: Disposal of the dead birds } \\
\hline Mode of disposal & Frequency and percentage \\
& $(\mathrm{N}=100)$ \\
\hline Thrown away in open areas & 23 \\
Buried under the ground & 39 \\
Both & 38 \\
\hline
\end{tabular}

$\chi^{2}=0.908$ at $2 \mathrm{df}$ (Non-significant)

\subsection{Health care}

\subsubsection{Treatment}

Table 9 shows that $63 \%$ of the respondents treated their birds themselves, $25 \%$ treated by government veterinarian and $12 \%$ treated by private veterinary practitioner when their birds showed symptoms of disease or sickness.

This might be due to the reason that other than the city of Aizawl, veterinary service in the rural area was poor. So, farmers had to treat their birds themselves when they saw disease symptoms.

\begin{tabular}{lc}
\hline Table 9: Treatment of birds & \\
\hline Mode of treatment & $\begin{array}{c}\text { Frequency and } \\
\text { percentage }(\mathrm{N}=100)\end{array}$ \\
\hline By self & 63 \\
By government veterinarian & 25 \\
By private veterinary practitioner & 12 \\
\hline$\chi^{2}=2.68$ at 2 df (Non-significant) &
\end{tabular}




\subsubsection{Sources of vaccine}

Table 10 reveals that majority of the broiler farmers (53\%) procured vaccine from the feed dealer, $23 \%$ from the open market, while 15\% procured from the government staff, 6 percent from the private practitioner and $3 \%$ procured vaccine from the government veterinarian.

Most of the farmers procured vaccine from the feed dealer as feed dealer was in close contact with the farmers. Farmers not only procured feed but also procured medicine, vaccine and other inputs required for broiler farming. Poultry feed dealer also organized training for them on broiler farming practices such as how to vaccinate the birds.

Table 10: Sources of vaccine

\begin{tabular}{lc}
\hline Source & $\begin{array}{c}\text { Frequency and } \\
\text { percentage }(\mathrm{N}=100)\end{array}$ \\
\hline Open market & 23 \\
Feed dealer & 53 \\
Government staff & 15 \\
Private practitioner & 6 \\
Government veterinarian & 3 \\
\hline
\end{tabular}

$\chi^{2}=6.491$ at $4 \mathrm{df}$ (Non-significant)

\subsubsection{Type of vaccine}

Table 11 shows that 47 percent of the respondents used only IBD vaccine followed by only ND vaccine (30\%), while 23 percent respondents used both IBD and ND vaccine.

Rahman (2015) reported that $3 \%$ of the respondents vaccinated their birds against one disease and the same dewormed their birds while majority (93\%) of the farmers used antibiotic when the birds suffered from a disease. ND is given at 7-day age and IBD is given at 2-week age. However, the respondents did not follow this schedule always due to one or the other reason such as availability of vaccine, disease outbreak and lack of knowledge.

\begin{tabular}{lc}
\hline \multicolumn{2}{l}{ Table 11: Vaccines used by the respondents } \\
\hline Vaccine & Frequency and percentage $(\mathrm{N}=100)$ \\
\hline IBD only & 47 \\
ND only & 30 \\
Both IBD and ND & 23 \\
\hline
\end{tabular}

$\chi^{2}=0.201$ at $2 \mathrm{df}$ (Non-significant)

\subsubsection{Expenditure on vaccine and medicine}

Majority of the broiler farmers (53\%) spent ₹ 450-1,500 for vaccine and medicine followed by $42 \%$ spending more than $₹$ 1,500 and $5 \%$ spent less than $₹ 450$ for vaccine and medicine (Table 12).

Nath et al. (2013) reported that feed cost alone contributed $90.95 \%$ to the total cost of production followed by chick cost,

\begin{tabular}{lcc}
\hline \multicolumn{3}{l}{ Table 12: Expenditure incurred on vaccine and medicine } \\
\hline Expenditure (₹) & $\begin{array}{c}\text { Frequency and per- } \\
\text { centage }(\mathrm{N}=100)\end{array}$ & Mean \pm SD \\
\hline Below 450 & 5 & $1004.38 \pm$ \\
$450-1,500$ & 53 & 543.95 \\
Above 1,500 & 42 & \\
\hline$\chi^{2}=64.055$ at 2 df (Non-significant)
\end{tabular}

medicine cost and vaccine cost in backyard poultry farming in Sikkim. As compared to the number of birds farmers spent less on vaccine and medicine which might be due to the reason that most of the farmers did not vaccinate their birds regularly and some never vaccinated their birds. Medicine (mineral mixture and vitamins) was also given irregularly. They administered medicine mainly when their birds became sick. Another reason might be due to the lack of availability of vaccine and medicine in the rural areas on time.

\subsection{Marketing}

\subsubsection{Price of chick, broiler and feed}

The result shows that the average price per chick and per $\mathrm{kg}$ live broiler was ₹ 45 and ₹ 150, respectively. Available in $50 \mathrm{~kg}$ and $70 \mathrm{~kg}$ bag the average price per kg feed was ₹ 38 (Table 13).

In comparison to the neighbouring states (Assam, Manipur and Nagaland) the price of chick, broiler and feed was higher in Mizoram which was mainly due to higher transportation cost. If there was any problem in the transportation it would affect the price. Also prices were unstable throughout the year.

\begin{tabular}{lcc}
\hline \multicolumn{3}{l}{ Table 13: Price of chick, broiler and feed } \\
\hline Item & Price range (₹) & Average \\
\hline Chick & $40-50$ per chick & 45 per chick \\
Broiler & $140-160$ per kg & 150 per kg live \\
& live weight & weight \\
Feed & $35-40$ per kg & 38 per kg \\
\hline
\end{tabular}

\subsubsection{Selling age and weight}

Table 14 shows that the average age of birds sold in the market was 3 months and the average weight of birds sold in the market was $3 \mathrm{~kg}$.

Due to unstable market birds were not sold at desirable age and weight. Sometimes birds were sold at $1 \mathrm{~kg}$, sometimes at $5 \mathrm{~kg}$ according to the need and convenience of the farmers.

\begin{tabular}{lcc}
\hline \multicolumn{4}{l}{ Table 14: Age and weight of birds sold } \\
\hline Item & Range & Average \\
\hline Age & $1-5$ months & 3 months \\
Weight & $1-5 \mathrm{~kg}$ & $3 \mathrm{~kg}$ \\
\hline
\end{tabular}

\subsubsection{Mode of selling the birds}

More than half (54\%) of the respondents sold their birds in the 
village market, $16 \%$ sold to hotel and restaurant, $13 \%$ sold in nearby urban areas, $12 \%$ sold to dealer as per contract, and $5 \%$ sold their birds to the neighbours (Table 15 ).

Rahman (2015) observed that farmers procured chicks from local market of Aizawl city at ₹ 40-50 per chick and the price of feed was ₹ 30-45 per kg. Sixty percent sold birds at the age above 3 months or when the birds attained 3-4 kg live body weight. Majority (77\%) of the respondents sold their birds in wholesale market at ₹ 130-150 and in retail market at ₹ 160180. Majority sold their birds in the village market mainly due to the availability of marketing place and customers. Some sold to hotel and restaurant mainly due to the demand of more birds. Fluctuation in price of feed, mortality of chicks especially in rainy and winter season and import of broiler from neighbouring state in cheaper price made marketing unreliable.

\begin{tabular}{lcc}
\hline \multicolumn{3}{l}{ Table 15: Mode of selling the birds } \\
\hline Mode of selling & $\begin{array}{c}\text { Frequency and } \\
\text { percentage }(\mathrm{N}=100)\end{array}$ & Average \\
\hline Village market & 54 & 3 months \\
Hotel and restaurant & 16 & $3 \mathrm{~kg}$ \\
Dealer as per con- & 12 & \\
tract & & \\
Nearby urban areas & 13 & 5 \\
Neighbours & 5 \\
$\chi^{2}=11.006$ at 4 df (Non-significant)
\end{tabular}

\section{Conclusion}

Farmers should be made aware about the need for vaccination on time as well as the need for adopting a scientific system of rearing. Marketing service should be provided along with the provision of veterinary service. There is a scope for research on extension education service need assessment of the broiler farmers. There is also a scope to study economic, social and environmental sustainability of broiler farming. Also there is a need to conduct research on marketing.

\section{References}

Adekomaya, O.S., 2012. Adaption of biomass-fire incinerator in poultry mortality management. International Journal of Energy, Environmental Engineering 1(2), 75-76.

Angela, L.R., 2014. Effect of age and rearing system on the performance of broiler in Mizoram. MVSc Thesis, Central Agricultural University, Imphal, India.

Banday, M.T., Risam, K.S., 2001. Growth performance and carcass characteristics of broiler chicken fed with probiotics. Indian Journal of Poultry Science 36(3), 252-255.

Bolder, N.M., Ledoux, L., 2002. Gereral protocol for clean disinfecting poultry house. Poultry World 18(12), 26-29.

Elizabeth, L.L., 2012. Effect of feeding frequency on the performance of broiler. MVSc Thesis, Central Agricultural University, Imphal, India.

Elizabeth, Y., Saptoca, D., Saharia, K.K., 2011. Poultry farmers of Kohima and Dimapur districts of Nagaland: A profile. Tamil Nadu Journal of Veterinary \& Animal Science 7(3), 210-212.

Ezeibe, A.B.C., Okorji, E.C., Chah, J.M., Abudei, R.N., 2014. Impact of entrepreneurship training on rural poultry farmers' adoption of improved management practices in Enugu state, Nigeria. Academic Journal 9(20), 1604-1609.

Mapiye, C., Sibanda, S., 2005. Constrains and opportunities of village chicken production systems in the small holder sector of Rushinga district of Zimbabwe. Livestock Research for Rural Development 27(4). http://www. Irrd.apav.org.co/irrd17/10/mapi17115.htm. Accessed on 22 February 2017.

Mozumdar, L., Farid, K.S., Ahmed, J.U., Rahman, M.W., 2009. Broiler farming: an approach to improve rural livelihood. Journal of Bangladesh Agricultural University 7(2), 395-402.

Nath, B.G., Pathak, P.K., Mohanty, A.K., 2013. Scientific backyard poultry rearing technology: an approach to awareness and adoption of technology for livelihood development of rural farmers in Sikkim, India. Russian Journal of Agriculture \& Socio-economic Science 22(3), 38-43.

Pratab, R., Carin, R., 2015. Current Opportunity in India's Poultry Sector. A Broader Consultancy India Pvt. Ltd., Goa.

Rahman, S., 2015. Management of broiler farms in Aizawl dristrict of Mizoram, India. Livestock Research for Rural Development 27(4). http://www.Irrd.org/Irrd27/4/ cont2704.htm. Accessed on 26 October 2016.

Rath, P.K., Mandal, K.D., Panda, P., 2015. Backyard poultry farming in India: A call for skill upliftment. Research Journal of Recent Science 4, 1-5. 